\title{
Enzymatic PET Degradation
}

\author{
Athena Papadopouloư ${ }^{\S}$ Katrin Hecht ${ }^{\S}$, and Rebecca Buller*
}

\begin{abstract}
Plastic, in the form of packaging material, disposables, clothing and other articles with a short lifespan, has become an indispensable part of our everyday life. The increased production and use of plastic, however, accelerates the accumulation of plastic waste and poses an increasing burden on the environment with negative effects on biodiversity and human health. PET, a common thermoplastic, is recycled in many countries via thermal, mechanical and chemical means. Recently, several enzymes have been identified capable of degrading this recalcitrant plastic, opening possibilities for the biological recycling of the omnipresent material. In this review, we analyze the current knowledge of enzymatic PET degradation and discuss advances in improving the involved enzymes via protein engineering. Looking forward, the use of plastic degrading enzymes may facilitate sustainable plastic waste management and become an important tool for the realization of a circular plastic economy.
\end{abstract}

Keywords: Biocatalysis · Biodegradation · Enzyme engineering · Plastic recycling $\cdot$ PET

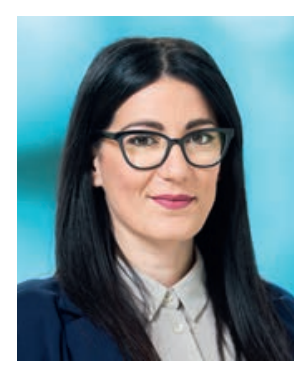

Dr. Athena Papadopoulou studied Biology and received her BSc from the University of Ioannina. She completed her MSc in Chemistry with a focus on Chemical and Biochemical Technologies. In 2013 she moved to Biotechnology group at the University of Ioannina to pursue her $\mathrm{PhD}$ in biocatalysis and enzyme technology. She is currently conducting her post-doctoral research at the Biocatalysis group of Prof. Rebecca Buller, at Zurich University of Applied Sciences ZHAW.

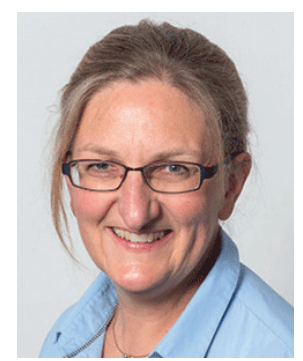

Dr. Katrin Hecht has a degree in Biology (University of Regensburg, Germany) and Human Nutrition (ETH Zürich). Her main interest is in the structure and function of proteins, which she studied previously in various prokaryotic (E. coli, Salmonella thyphimurium), and eukaryotic organisms (Saccharomyces cerevisiae, Pichia pastoris, mammalian cells), as well as archaebacteria (Haloferax). Since 2016 she is working as a project manager at $\mathrm{CCBIO}$.

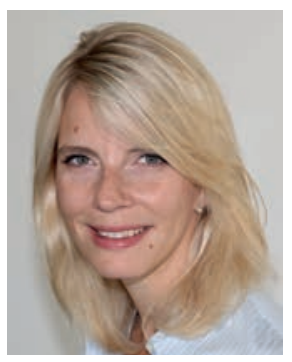

Rebecca Buller obtained her $\mathrm{PhD}$ (2011) from ETH Zurich, Switzerland (Prof. Dr. D. Hilvert) before she accepted a position as laboratory head at Firmenich, a flavor and fragrance company. Since 2015, she is Professor for Chemical and Biotechnological Methods, Systems and Processes at the Zurich University of Applied Sciences and leads the Swiss Competence Center for Biocatalysis (CCBIO). Her research interests include the expansion of the biocatalytic toolbox by sourcing and engineering enzymes for synthetic applications.

\section{Introduction}

Plastic has become an omnipresent material in our daily life and, as a consequence, the plastic industry has become the seventh most important industry in Europe, employing more than 1.5 million people with a turnover of 355 billion Euros in 2017. ${ }^{[1]}$ Plastic production is cheap and the generated plastic items are durable and versatile. The material is lightweight leading to cost savings in transportation and its use for packaging prevents food from spoiling. However, these very properties simultaneously render plastic an environmental burden: Most plastics degrade poorly in nature and the low-cost production promotes one-time use and littering while depleting fossil resources.

Plastics are used in many sectors such as in building and construction, transportation, electrical devices, in electronics and in agriculture. Mainly, however, plastics are applied in household goods and personal care products, clothing and, in particular, in packaging (Fig. 1).[2] Most plastics used are synthetic polymers which can be classified into two categories: Thermoplastics, such as polyethylene (PE), polypropylene (PP) or polyethylene terephthalate (PET), which consist of molecular units joined end-toend into a series of long, single carbon or heteroatomic chains. Thermoplastics can be repeatedly softened and hardened by heating and cooling. Thermo-set plastics, on the other hand, include for example polyurethane and phenol-formaldehyde resins, which have a highly cross-linked structure. These plastics are designed to be molded into their final form, an irreversible process. ${ }^{[1]}$

In 2015, the total worldwide primary plastics production amounted to 407 million metric tons and the primary waste generation was estimated to be 302 million metric tons (Fig. 1).[2] Demand and production of plastic is continuously increasing and as a consequence the environmental burden due to the concomitant growth in waste volume is intensifying: More than $90 \%$ of the plastics applied in packaging are used once only and less than $10 \%$ of plastic packaging waste is currently recycled. ${ }^{[3]}$

\subsection{Plastic in the Environment and the Food Chain}

While the pollution of beaches with plastic bottles, shopping bags, disposables or fishing gear have garnered public attention, also the small things matter: Microplastics $(1 \mu \mathrm{m}-5 \mathrm{~mm})$ 


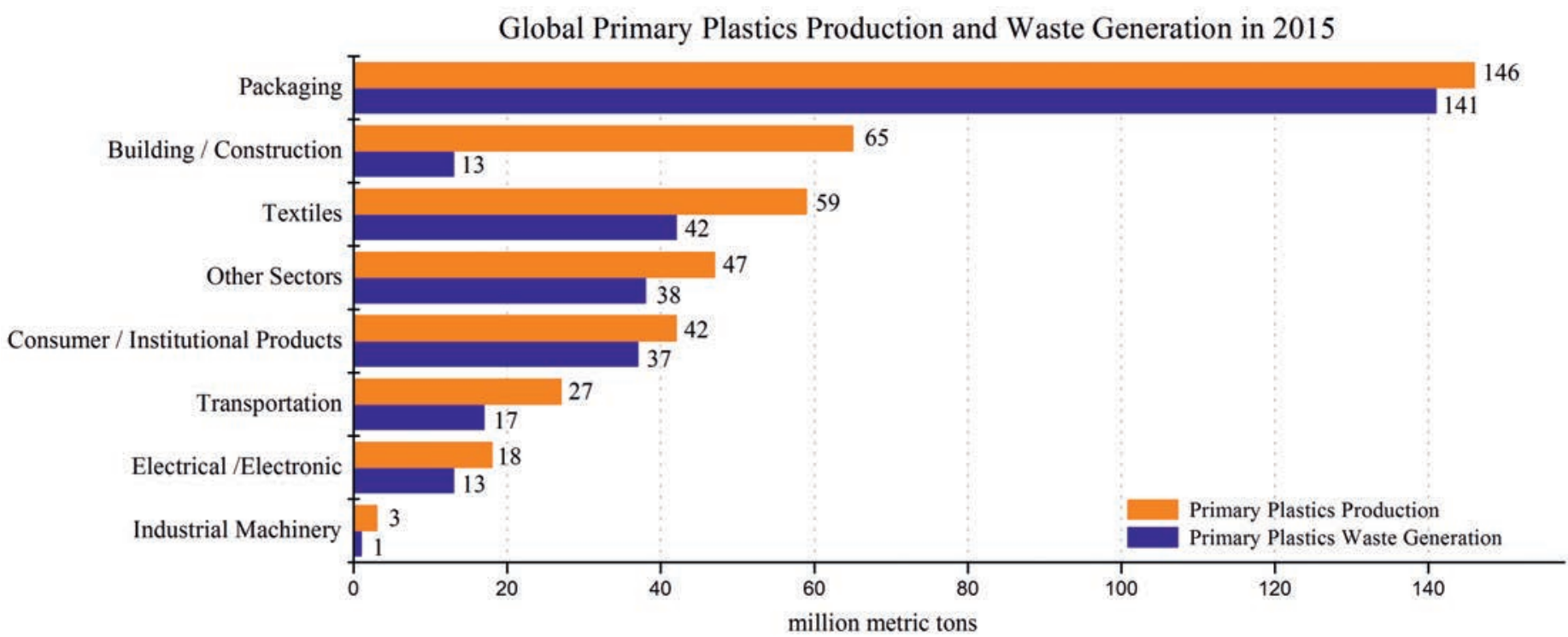

Fig. 1. Plastic is part of our everyday life. It is mainly used in packaging, building and construction as well as to produce household goods including textiles. Plastic waste is a major problem due to the accumulation of plastic debris in water, air and soil. Data presented refer to the global primary plastics production and primary waste generation (in million metric tons) in 2015 according to industrial use sector ${ }^{[2]}$

and nanoplastics $(1 \mathrm{~nm}-1 \mu \mathrm{m})^{[4]}$ are equally associated with a potential danger to the environment. Micro- and nanoplastics derive from different sources: They are released from synthetic clothes in the form of fibers ${ }^{[5]}$ while micro- and nanoplastic beads are part of personal care products (toothpaste, face wash). These so-called primary micro- and nanoplastics have been found in water, in fish and bivalves, ${ }^{[6]}$ in the air ${ }^{[7]}$ and in human lungs. ${ }^{[7 \mathrm{~b}]}$ By contrast, the secondary micro- and nanoplastics originate from plastic waste degradation. After exposure to sunlight, wind or sea, plastic debris stemming from landfills or from littering is ground into smaller particles posing a threat to marine wildlife as these particles are mistaken for food. In this way, plastic particles end up in the food chain and appear for example in fish and bivalves (mussels, oysters, scallops) sold for human consumption ${ }^{[6]}$ or in table salt. ${ }^{[8]}$ A preliminary study which detected microplastic in human stool samples was recently presented at the United European Gastroenterology week ${ }^{[9]}$ and together with a report estimating the amount of plastic ingested by humans annually[10] confirmed worries about effects on human health. ${ }^{[7 b, 11]}$

\subsection{Strategies to Reduce Plastic Waste}

A large part of the plastic waste produced in developed countries is not processed locally but is transported to other countries, where poor waste management strategies may result in inadequately disposed waste and a high risk of polluting the environment. ${ }^{[12]}$ In 2017 , Beijing announced at the meeting of the World Trade Organization in Geneva that the allowed import margin of global plastic waste into China will be reduced. ${ }^{[13]}$ Many other countries issued similar restrictions. As a result, strategies and measures designed to reduce plastic waste, ${ }^{[14]}$ improve recycling ${ }^{[15]}$ and to allow for the treatment of plastic waste locally are currently implemented by politics and industry. A successful European example is the collection and recycling of food PET bottles which works particularly well in countries with a disposal charge. The EU member states have a $90 \%$ collection target for plastic bottles by 2029 and by the end of 2030 plastic bottles will need to have a content of recycled material of at least $30 \% .{ }^{[16]}$ For a detailed discussion of the recycling strategies please refer to recent reviews. ${ }^{[3,15,17]}$

\subsection{PET Recycling}

PET is a semi-crystalline, thermoplastic polyester consisting of the building blocks ethylene glycol (EG) and terephthalic acid (TPA) linked via ester bonds. ${ }^{[18]}$ Commercial synthesis of PET either starts with EG/TPA or EG/dimethyl terephthalate (DMT). Upon heating bis(2-hydroxyethyl) terephthalate (BHET) is formed, which reacts further to form PET (Scheme 1). Depending on the desired molecular weight, two or three polymerization steps follow.

Due to its low cost, durability and excellent food packaging properties, PET is one of the most sought-after plastics and covers more than half of the global demand of synthetic fibers and bottles. In 2017 the world PET resin production had a capacity of more than 30 million tons. ${ }^{[19]}$ Thermal (incineration, pyrolysis),
Scheme 1. Schematic representation of possible PET synthesis pathways (adapted from ref. [18]).

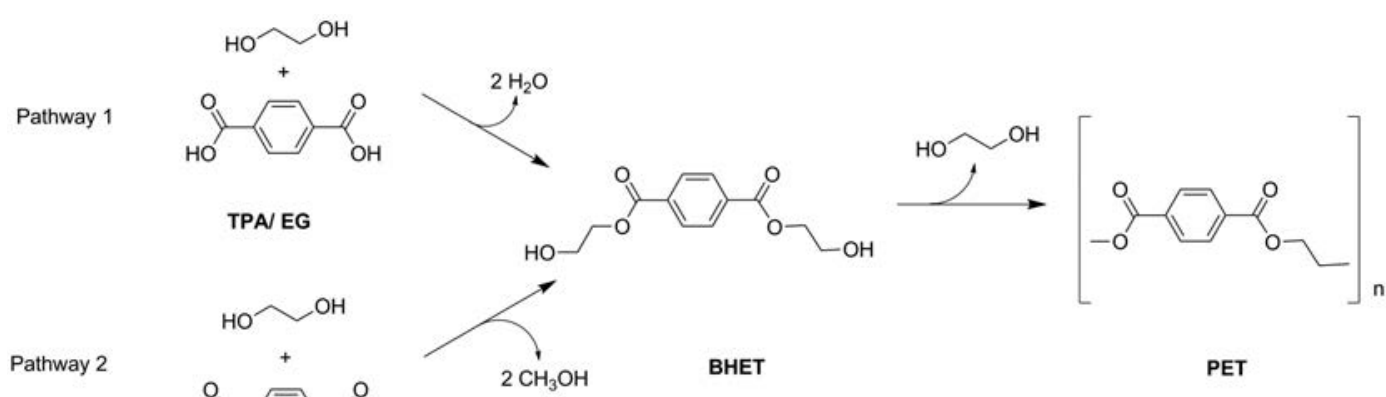

DMT/EG 
Table 1. Examples of reported PET hydrolysing enzymes and microbes (not exhaustive).

\begin{tabular}{|c|c|c|c|}
\hline $\begin{array}{l}\text { Enzyme } \\
\text { (if specified) }\end{array}$ & Source & Substrate & Ref. \\
\hline $\mathrm{TfH}$ & Thermobifida fusca & $\begin{array}{l}\text { Melt pressed PET from beverage bottle } \\
\text { (10\% crystallinity) }\end{array}$ & [25] \\
\hline $\mathrm{HiC}$ & Thermomyces insolens & $\begin{array}{l}l c \text { PET ( } 7 \% \text { crystallinity), } \\
\text { boPET ( } 35 \% \text { crystallinity) }\end{array}$ & [26] \\
\hline Thh_Est & Thermobifida halotolerans & PET film (properties not reported) & [27] \\
\hline \multirow[t]{2}{*}{ LC-Cutinase } & Metagenome from leaf branch compost & Amorphous PET film & {$[28]$} \\
\hline & Nocardia species & PET transparency sheets & [29] \\
\hline $\begin{array}{l}\text { Tcur1278 } \\
\text { Tcur0390 }\end{array}$ & Thermomonospora curvata & Nanoparticles of $l c$ PET film & [30] \\
\hline \multirow[t]{4}{*}{$\begin{array}{l}\text { Cut190 (S226P/ } \\
\text { R228S) }\end{array}$} & Saccharomonospora viridis & $\begin{array}{l}l c \text { PET ( } 6-7 \% \text { crystallinity) } \\
\text { PET film for packaging (PET-S) } \\
\text { ( } 8.3 \% \text { crystallinity) }\end{array}$ & {$[31]$} \\
\hline & Comamonas testosterone F6. & $\begin{array}{l}\text { Micro-size PET particles ( } 23 \% \text { crystalli- } \\
\text { nity) }\end{array}$ & [32] \\
\hline & Uncultured bacterium & Amorphous PET foil & [33] \\
\hline & Streptomyces species & Powdered PET from beverage bottle & [34] \\
\hline PETase & Ideonella sakaiensis 201-F6 & $\begin{array}{l}l c \text { PET ( } 1.9 \% \text { crystallinity) and high crys- } \\
\text { tallinity } h c \text { PET (commercial bottle) }\end{array}$ & [35] \\
\hline
\end{tabular}

material (crushing) as well as chemical recycling strategies have been implemented ${ }^{[20]}$ over the years and the use of recycled PET to produce food-packaging has been approved. ${ }^{[21]}$ But despite all efforts, finding an efficient, environmentally friendly way to chemically recycle PET is still a challenge. ${ }^{[22]}$ In chemical recycling one targets to transform plastic waste into products with higher added value or to depolymerize used plastic to its monomers followed by repolymerization. ${ }^{[23]}$ Proof-of-concept studies on pure polymers, demonstrate successful recovery of the monomeric building blocks. Biological recycling follows similar principles as chemical recycling but was originally restricted to biodegradable plastics. PET has long been thought to have only limited biodegradability due to the presence of the aromatic TPA units in its backbone that restrict the mobility of its polymer chains. ${ }^{[24]}$ Additionally, PET is semi-crystalline, which negatively affects enzyme accessibility and consequently its potential for biological degradation. Recent research, however, has identified enzymes that are also able to degrade recalcitrant plastics like PET (Table 1).

\section{Examples of PET-degrading Enzymes and Microbes}

In 2005 Müller et al. showed for the first time that PET can be degraded by a polyester hydrolase from a Thermobifida species (TfH). Using a melt-pressed PET sample from a beverage bottle with $10 \%$ crystallinity, the study showed a weight loss of around $50 \%$ after three weeks of incubation at $55{ }^{\circ} \mathrm{C}$ with the microorganism. ${ }^{[25]}$

This initial finding triggered extensive studies of the related cutinases from T. fusca and other Thermobifida species. ${ }^{[27,36] ~ I n ~}$ 2009, Ronkvist et al. reported a cutinase from Thermomyces insolens that reached almost complete degradation of low-crystallinity (lc)PET with $7 \%$ crystallinity after $96 \mathrm{~h}$ at $70{ }^{\circ} \mathrm{C} .{ }^{[26]}$ However, enzymatic efficiency decreased significantly and almost no weight loss was observed when biaxially oriented (bo)PET with $35 \%$ crystallinity was used. Sulaiman et al. reported an LC-cutinase with $57.4 \%$ sequence identity to the cutinase from $T$. fusca with the ability to degrade PET materials. The enzyme was isolated from leaf-branch compost by a metagenomics approach and showed a degradation yield of approximately $25 \%$ after $24 \mathrm{~h}$ of incubation at $70{ }^{\circ} \mathrm{C} .{ }^{[28]}$ Sharon and Sharon studied the biodegradation of PET films by naturally growing microbes, mainly fungi and actinomyces. Their results confirm a slow microbial degradation of PET film by Nocardia with the help of an esterase.[29]

In 2014, two putative polyester hydrolases were cloned from the thermophilic actinomycete Thermomonospora curvata by Wei et al. The authors showed that these enzymes can degrade PET nanoparticles with unknown crystallinity at temperatures of up to $50{ }^{\circ} \mathrm{C}$. However, their thermostability profile $\left(\leq 50{ }^{\circ} \mathrm{C}\right)$ could limit their application at higher temperatures and thus their efficient degradation of PET films. ${ }^{[30]}$ Kawai et al. cloned a cutinase-like polyesterase from Saccharomonospora viridis capable of degrading a PET-film (no crystallinity reported) with up to $27 \%$ weight loss at $63{ }^{\circ} \mathrm{C}$ after 3 days. The presence of $\mathrm{Ca}^{2+}$ in the reaction mixture increased the activity of the enzyme. Calcium anions are assumed to bind to the surface acidic amino acids of the enzyme leading to changes in the tertiary structure required for full activity. ${ }^{[31]}$

Gong et al. combined biology with a chemical process by using whole cell biocatalysts consisting of Camamonas testosterone F6 under alkaline conditions for the biodegradation of PET. Micro-size PET particles with $23 \%$ crystallinity were used as substrate and after $48 \mathrm{~h}$ at $37^{\circ} \mathrm{C}$ the crystallinity of PET was increased by $1.5 \%$ indicating that low crystallinity or amorphous areas in PET are more likely to be degraded by the enzymes. ${ }^{[32]}$ Similarly, a combined physical and a biological PET degradation process was reported by Farzi et al. ${ }^{[34]}$ In this study Streptomyces species were mixed together with PET bottles that had been powdered into different particle sizes. Results showed that the size of the particles as well as the incubation time had a profound effect on PET degradation. Almost $70 \%$ degradation was observed after 18 days at $28{ }^{\circ} \mathrm{C}$ for the smallest particle size $(212 \mu \mathrm{m})$ while in case of larger particles $(500 \mu \mathrm{m})$ only $50 \%$ degradation was de- 


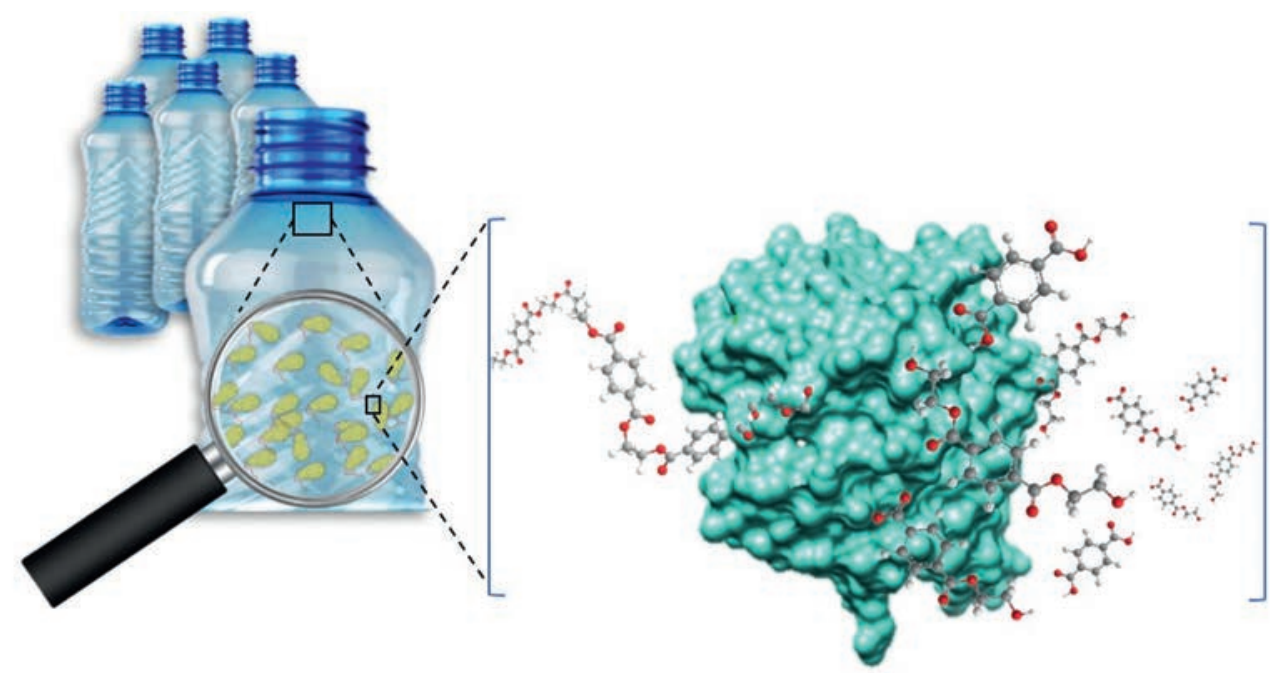

Fig. 2. Schematic representation of PET degradation by Ideonella sakaiensis using its plastic degrading enzyme PETase. Adapted from ref. [37].

tected. Unfortunately, when PET films were used, the biodegradation was very low and no significant changes of the film surface morphology were observed.

Recently, a further promising candidate for PET degradation with superior activity against PET compared to the other enzymes was discovered. Yoshida et al. reported a Gram-negative bacterium Ideonella sakaiensis 201-F6 which can effectively use PET as a carbon source by utilizing two enzymes named PETase and MHETase. ${ }^{[35]}$ Since its discovery in 2016, PETase has received increasing attention due to its ability to degrade PET at moderate temperatures, potentially providing a green solution to reduce PET accumulation in the environment (Fig. 2).

\section{PETase from Ideonella sakaiensis}

In 2016, a Japanese group collected 250 environmental samples from a PET bottle recycling site to screen them for microorganisms with the ability to use PET as a carbon source for growth. A microbial consortium was observed on a PET film sample that caused changes to the morphology of the material. Among the many microorganisms that grew on the PET film, the Japanese group succeeded to identify the Gram-negative bacterium responsible for degradation. This new strain, which was named Ideonella sakaiensis, led to a complete degradation of the PET film after 6 weeks at $30{ }^{\circ} \mathrm{C}$.

The authors could show that two enzymes were responsible for the PET hydrolysis. ${ }^{[35]}$ The bacteria secrete an enzyme that can hydrolyze PET film to mono(2-hydroxyethyl) terephtalic acid (MHET) as a major product with minor amounts of bis(2-hydroxyethyl) terephtalic acid (BHET) and terepthalic acid (TPA). This enzyme, dubbed PETase, showed only $51 \%$ amino acid sequence identity with the PET hydrolase from Thermobifida fusca (TfH).

Together with PETase, a second enzyme, crucial for the complete PET degradation was identified. The MHET hydrolase (or MHETase) which was initially assigned to the tannase family, uses MHET as a substrate to convert it to TPA and ethylene glycol. A recent structural characterization of MHETase revealed its structural similarity with feruloyl esterases and suggested that a natural evolution through a loop modification in the lid domain might have led to the high substrate specificity of the enzyme. ${ }^{[38]}$ Unlike other tannases and feruloyl esterases, MHETase showed no activity against PET, BHET, pNP aliphatic esters or typical aromatic esters. The PETase/MHETase system exhibited efficient PET degradation activity at room temperature. Moreover, when compared with other PET hydrolytic enzymes like LC-cutinase, F. Solani cutinase (FsC) and $\mathrm{TfH}$ for their ability to degrade PET film and BHET at $30{ }^{\circ} \mathrm{C}$ and $\mathrm{pH}$ 7.0, a 5.5-fold, 88-fold and 120-fold increase in activity was found, respectively. Higher performance of PETase compared with the other three cutinases was also found when high crystallinity $(h c)$ PET was used as a substrate, highlighting its promising activity for the degradation of resistant PET plastic at a moderate temperature.

\section{Structure of PETase}

In order to understand the superior performance of PETase compared to previously known plastic degrading enzymes, several studies have focused on the structure elucidation of PETase. Based on the cutinase model (its closest homolog as predicted from the sequence alignment), PETase belongs to the $\alpha / \beta$ hydrolase superfamily. The core of the enzyme folds to nine $\beta$-strands surrounded by seven $\alpha$-helices while the active site, located at the surface of the protein, contains the conserved catalytic triad Ser160-His237-Asp206 (Fig. 3). [39]

Unlike other PET-hydrolyzing enzymes, PETase monomers form two intramolecular disulfide bridges (DS1 and DS2) (Fig. 3 ). DS1 is located near the active site and connects the $\beta 7-\alpha 5$ and

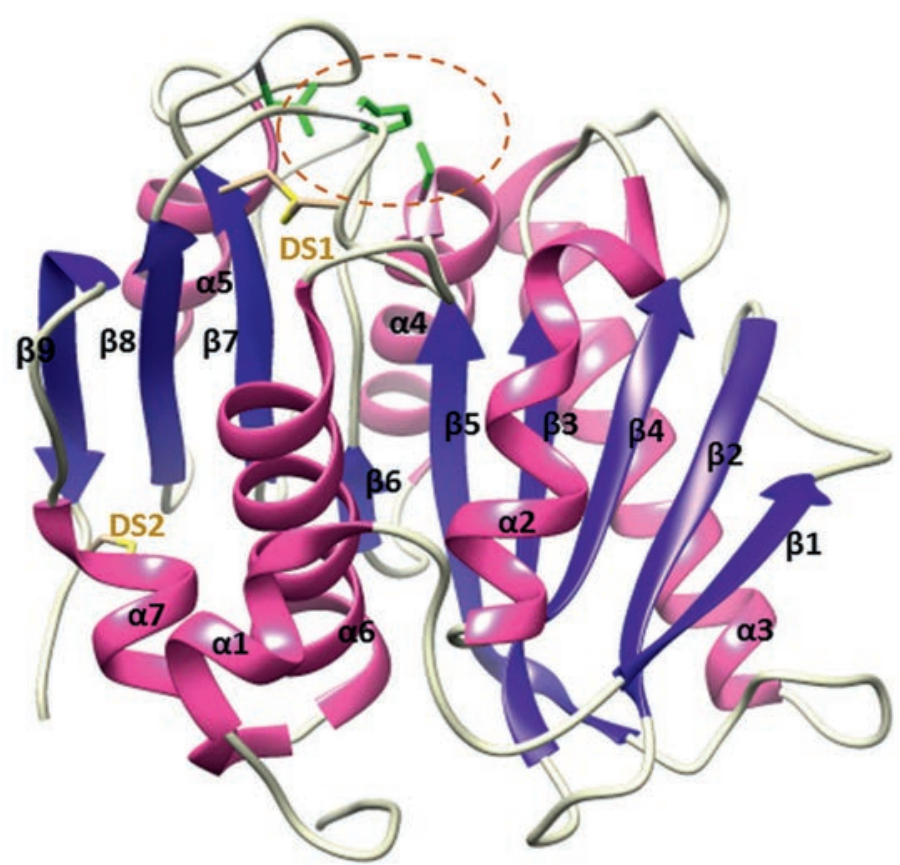

Fig. 3. Cartoon representation of the structural elements of the apoform of PETase (PDB code: $5 \mathrm{XJH}$ ). The residues of the catalytic triad of PETase, highlighted with an orange cycle, are colored green and are depicted in the stick representation. The disulfide bridges DS1 and DS2 are highlighted in yellow. 
$\beta 8-\alpha 6$ loops. Mutagenesis and molecular simulation studies have shown that DS1 is correlated with the integrity of the catalytic triad keeping the residues at functional positions and thus the enzyme active. Moreover, DS1 facilitates loop flexibility close to the binding site of the enzyme $(\beta 8-\alpha 6){ }^{[40]}$ Interestingly, this critical loop is three residues longer compared to other PET hydrolyzing enzymes allowing the formation of an extended binding site called 'subsite' for PET binding. [39] The high flexibility of this loop has also been connected to the superior activity of PETase at room temperature compared to other cutinases. ${ }^{[40 a]}$ The other disulfide bond, DS2, is conserved in all homologs and found close to the C-terminus of the enzyme. It links the C-terminal loop with the last helix. Since it is located far from the active site, DS2 has been linked to structural stability of the protein molecule. ${ }^{[39]}$

Tryptophan wobbling is another interesting PETase-related feature. Trp185, which is located close to the active site, is a highly conserved residue among the PET hydrolyzing enzymes. ${ }^{[40 \mathrm{~b}]}$ In the crystal structure of PETase three different conformations of this residue have been observed and were named A, B and C, respectively. Interestingly, PETase substrate binding only takes place when the critical tryptophan residue adopts the B conformation. Notably, in structures of homologous enzymes, a spatially close histidine residue (instead of a serine in PETase) locks the tryptophan exclusively in the $\mathrm{C}$ conformation. Not surprisingly, replacement of the native serine to a histidine led to PETase variants with a lower activity on PET, confirming the high significance of this amino acid to the catalytic behavior of the enzyme.[40c]

\subsection{Catalytic Mechanism of PETase}

Biological PET degradation leads to the production of mono(2hydroxyethyl) terephthalic acid, bis-(2-hydroxyethyl) terephthal- ic acid and terephthalic acid. Binding of PET into the active site of the PETase has been studied via structural investigations and molecular simulations of PETase employing substrate analogs. [39,40a,c] In essence, the catalytic mechanism for PET degradation follows the classical hydrolysis reaction of cutinases except for the W185 movement that contributes both to the binding and release of the product. Particularly, the substrate binds into the shallow cleft of the active site of the enzyme mainly through hydrophobic interactions and is further stabilized by the pi-stacking force of W185 in B conformation. The carbonyl group of the substrate is positioned close to the catalytic triad for the nucleophilic attack while the oxyanion hole stabilizes the tetrahedral intermediate. The subsequent step of the acyl-enzyme intermediate formation and the second nucleophilic attack is similar to typical hydrolytic reactions. After the cleavage of the ester bond the stronger pi-stacking interaction of the benzoic group with the W185 leads to rotation and release of the product from the active center (Fig. 4). ${ }^{[40 c]}$

\section{Improving PETase Activity}

Despite its prominent contribution to PET degradation, the application of PETase at larger scale remains a key challenge. In this context, enzyme engineering offers a valuable tool to improve the properties of the biocatalyst and expand its use to actual applications.

The significance of the substrate-binding pocket residues on enzyme activity has been highlighted in several studies. A structure-guided site-directed mutagenesis of PETase afforded mutants with, for example, a wider substrate pocket or enhanced aromaticity which showed increased degradation activity towards a PET drinking bottle compared to the wildtype. ${ }^{[41]}$ Moreover, substitution of a polar residue located distal from the catalytic site with a

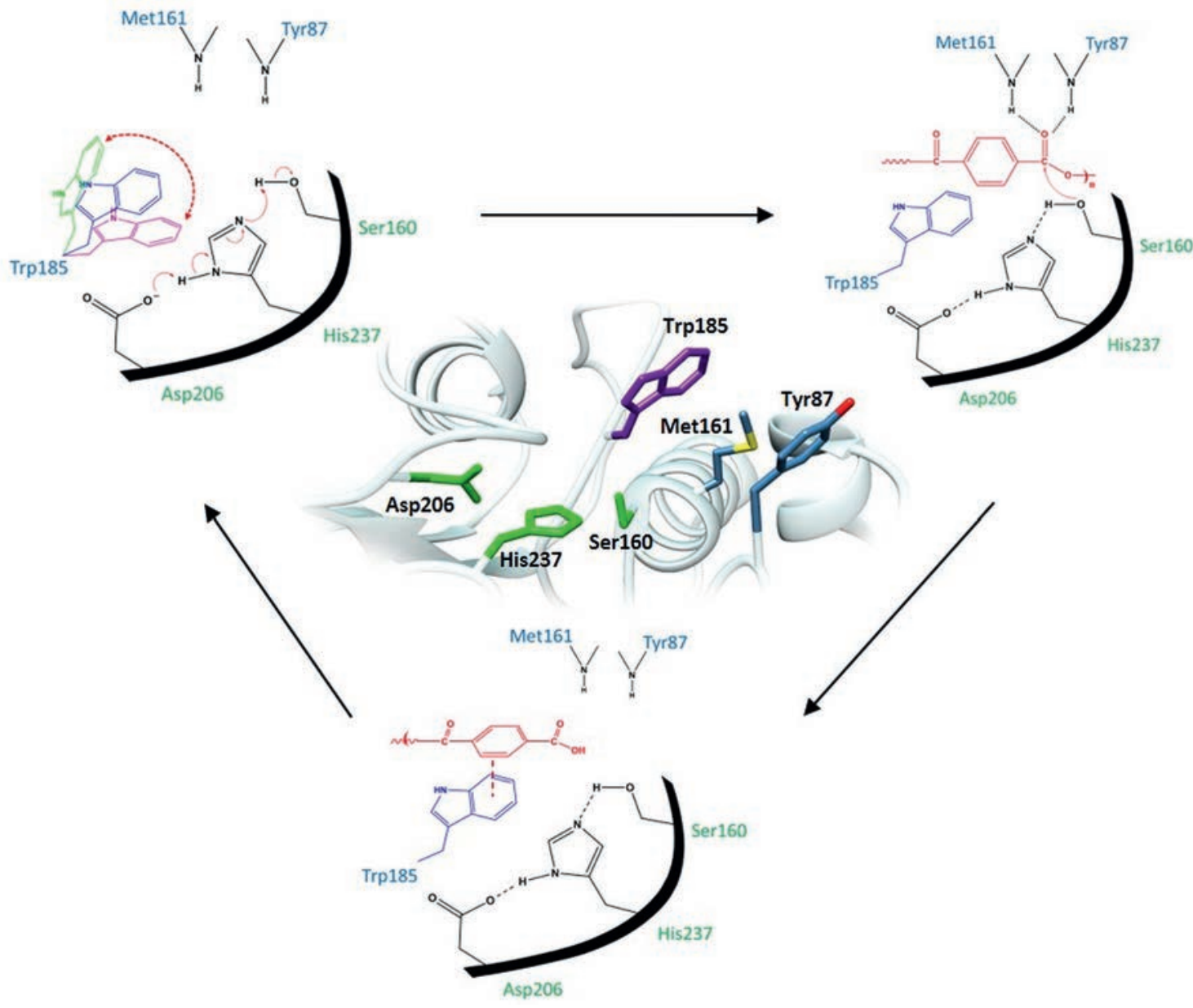

Fig. 4. Catalytic mechanism of PETase. The amino acids building the catalytic triad of PETase are presented as green sticks, the crucial site tryptophan is shown in purple and residues constituting the oxyanion hole are depicted in blue. 
small hydrophobic amino acid resulted in a more stable enzyme complex with longer substrates such as PET film and increased activity by $32.4 \%$ after $36 \mathrm{~h}$ of reaction. ${ }^{[39]}$ In another study, rational design was used to alter the geometry of the substrate binding groove and a mutant with a 2.5 -fold improved activity towards PET film was generated. The observed higher activity was attributed to a stronger localization of the substrate at the binding site of the enzyme. ${ }^{[42]}$

One of the major differences of PETase compared to its closest homologs, cutinases, is its broader, open active-site cleft. Inspired by cutinase architecture, Austin et al. narrowed the binding cleft of PETase via exchange of two active site residues to conserved amino acids of homologous cutinases. The resulting double mutant showed a 3.8-fold improved PET degradation activity compared to the wild type enzyme due to an increased binding affinity to the substrate as calculated by molecular docking simulations. In the same study, the authors also succeeded to expand the substrate scope of PETase, demonstrating its ability to degrade a semiaromatic polyester named polyethylene-2,5-furandicarboxylate (PEF), a biobased PET replacement. As for PET, the double mutant showed a higher affinity towards PEF resulting in a more active enzyme. ${ }^{[40 \mathrm{~b}]}$

Apart from PET and PEF, a large number of other polyesters are industrially produced and their degradation remains difficult. To address this challenge, Liu et al. expanded the substrate specificity of PETase towards naphthyl esters. Based on sequence and structural analysis, the authors altered the hydrophobicity and the size of three key residues located close to the catalytic center and the resulting mutants showed up to 4.3-fold higher hydrolytic activity towards naphthyl esters compared to the wildtype enzyme.[43]

Not only the modest PET degradation activity but also PETase's low thermal stability limits its practical application in recycling. Exploiting a rational protein engineering strategy, Son et al. addressed this point by screening PETase variants for higher thermal stability and improved PET degradation ability. Mutations at the $\beta 6-\beta 7$ connecting loop and in the binding site generated an improved triple mutant variant that exhibited an increase in the $\mathrm{T}_{\mathrm{m}}$ value by $8.8^{\circ} \mathrm{C}$ and a 14-fold PET degradation activity enhancement at $40{ }^{\circ} \mathrm{C}$ compared to the wild type PETase. ${ }^{[44]}$

\section{Outlook}

Most packaging products such as those made from PET are discarded within one year. ${ }^{[3]}$ This represents not only a substantial environmental burden with potential health risks for living beings but depletes petrol resources and misses economic opportunities. Biocatalytic PET degradation has emerged as a green alternative in PET recycling ${ }^{[2,32,45]}$ and, if further improved, may become a more widely applicable strategy for general plastic waste management.

First steps toward the industrialization of enzymatic plastic waste management are already being taken. The French company Carbios, for example, has developed a closed-loop bio-recycling concept for enzymatic PET degradation. ${ }^{[46]}$ The recovered monomers are repolymerized and the generated PET is used to produce new bottles consisting of $100 \%$ recycled material. Going one step beyond, Carbios teamed up with Limagrain Céréales Ingrédients and Bpifrance to found the joint-venture Carbolice. The new company, which entered a partnership with Novozymes in 2019, focuses on the development of biodegradable single-use plastics containing in-built enzyme pellets. After use or while scattered in the environment the plastic is degraded enzymatically to base molecules that are taken up and metabolized by microorganisms ensuring a full degradation of the plastics in nature. ${ }^{[47]}$

Despite these initial successes, the reliable biotechnological application of enzymes in PET degradation requires improvements in enzyme efficiency, enzyme temperature tolerance ${ }^{[45 a]}$ as well as the development of strategies to circumvent the competitive inhibition of the enzymes by degradation products MHET and
BHET. ${ }^{[48]}$ Plastic production began about 70 years ago. The fact that enzymes with the ability to hydrolyze ester bonds in PET are already found in Nature is a rare but encouraging example of rapid natural evolution. ${ }^{[37]}$ Building on this, additional screenings of natural habitats such as marine biofilms on plastic particles seem promising for the identification of enzymes able to degrade plastic other than PET. Exploiting the progress made over the last decade in protein engineering, this palette of naturally occurring plastic degrading enzymes can be further optimized to valuably contribute toward a circular plastic economy.

Received: July 2, 2019

[1] Plastics Europe, 'Plastics the facts 2018', An analysis of European plastics production, demand and waste data, https://www.swiss-plastics.ch/de/themen/daten-fakten/plastics-europe/, accessed 06.06.2019.

[2] R. Geyer, J. R. Jambeck, K. L. Law, Sci. Adv. 2017, 3, e1700782, DOI: 10.1126/sciadv.1700782.

[3] Ellen MacArthur Foundation, 'The New Plastics Economy: Rethinking the Future of Plastics', https://www.ellenmacarthurfoundation.org/publications/the-new-plastics-economy-rethinking-the-future-of-plastics, accessed 19.06.2019.

[4] J. Frias, R. Nash, Mar. Pollut. Bull. 2019, 138, 145, DOI: 10.1016/j.marpolbul.2018.11.022.

[5] a) M. C. Zambrano, J. J. Pawlak, J. Daystar, M. Ankeny, J. J. Cheng, R. A Venditti, Mar. Pollut. Bull. 2019, 142, 394, DOI: https://doi.org/10.1016/j. marpolbul.2019.02.062; b) N. L. Hartline, N. J. Bruce, S. N. Karba, E. O. Ruff, S. U. Sonar, P. A. Holden, Environ. Sci. Technol. 2016, 50, 11532, DOI: 10.1021/acs.est.6b03045.

[6] C. M. Rochman, A. Tahir, S. L. Williams, D. V. Baxa, R. Lam, J. T. Miller, F.-C. Teh, S. Werorilangi, S. J. Teh, Sci. Rep. 2015, 5, 14340, DOI: 10.1038/ srep14340.

[7] a) C. G. Liu, J. Li, Y. L. Zhang, L. Wang, J. Deng, Y. Gao, L. Yu, J. J. Zhang, H. W. Sun, Environ. Int. 2019, 128, 116, DOI: 10.1016/j.envint.2019.04.024; b) J. C. Prata, Environ. Pollut. 2018, 234, 115, DOI: 10.1016/j.envpol.2017.11.043.

[8] D. Yang, H. Shi, L. Li, J. Li, K. Jabeen, P. Kolandhasamy, Environ. Sci. Technol. 2015, 49, 13622, DOI: 10.1021/acs.est.5b03163.

[9] P. Schwabl, S. Köppel, P. Königshofer, T. Bucsics, M. Trauner, T. Reiberger, 'Assessment of Microplastic Comcentrations in Human Stool - Preliminary Results of a Prospective Study', http://www.professionalabstracts.com/ ueg2018/iplanner/\#/presentation/819, accessed 04.06.2019.

[10] K. D. Cox, G. A. Covernton, H. L. Davies, J. F. Dower, F. Juanes, S. E. Dudas, Environ. Sci. Technol. 2019, DOI: 10.1021/acs.est.9b01517.

[11] a) L. G. A. Barboza, A. D. Vethaak, B. Lavorante, A. K. Lundebye, L. Guilhermino, Mar. Pollut. Bull. 2018, 133, 336, DOI: 10.1016/j.marpolbul.2018.05.047; b) M. Carbery, W. O'Connor, P. Thavamani, Environ. Int. 2018, 115, 400, DOI: 10.1016/j.envint.2018.03.007; c) A. L. Lusher, P. C. H. Hollman, J. J. Mendoza-Hill, FAO Fisheries and Aquaculture Technical Paper. No. 615. Rome, Italy, 2017.

[12] J. R. Jambeck, R. Geyer, C. Wilcox, T. R. Siegler, M. Perryman, A. Andrady, R. Narayan, K. L. Law, Science 2015, 347, 768, DOI: 10.1126/ science. 1260352.

[13] T. Schauenberg, 'After China's import ban, where to with the world's waste?', https://www.dw.com/en/after-chinas-import-ban-where-to-withthe-worlds-waste/a-48213871, accessed 06.06.2019.

[14] D. Xanthos, T. R. Walker, Mar. Pollut. Bull. 2017, 118, 17, DOI: 10.1016/j. marpolbul.2017.02.048.

[15] J. M. Garcia, M. L. Robertson, Science 2017, 358, 870, DOI: 10.1126/science.aaq0324.

[16] Press Release, 'Parliament seals ban on throwaway plastics by 2021', http:// www.europarl.europa.eu/news/en/press-room/20190321IPR32111/parliament-seals-ban-on-throwaway-plastics-by-2021, accessed 06.06.2019.

[17] C. J. Rhodes, Sci. Progr. 2018, 101, 207, DOI: 10.3184/003685018X15294 876706211.

[18] K. H. Webb, J. Arnott, J. R. Crawford, P. E. Ivanova, Polymers 2013, 5, DOI: $10.3390 /$ polym5010001.

[19] PlasticsInsight, 'Polyethylene Terephthalate (PET): Production, Price, Market and its Properties', https://www.plasticsinsight.com/resin-intelligence/resin-prices/polyethylene-terephthalate/, accessed 06.06.2019.

[20] a) B. Geyer, G. Lorenz, A. Kandelbauer, Expr. Polym. Lett. 2016, 10, 559, DOI: 10.3144/expresspolymlett.2016.53; b) L. Zhou, X. M. Lu, Z. Y. Ju, B. Liu, H. Y. Yao, J. L. Xu, Q. Zhou, Y. F. Hu, S. J. Zhang, Green Chem. 2019, 21, 897, DOI: 10.1039/c8gc03791d.

[21] F. Welle, Resources Conservation and Recycling 2011, 55, 865, DOI: 10.1016/j.resconrec.2011.04.009. 
[22] A. M. Al-Sabagh, F. Z. Yehia, G. Eshaq, A. M. Rabie, A. E. ElMetwally, Egyptian J. Petrol. 2016, 25, 53, DOI: https://doi.org/10.1016/j. ejpe.2015.03.001.

[23] H. Sardon, A. P. Dove, Science 2018, 360, 380, DOI: 10.1126/science. aat4997.

[24] R. Wei, W. Zimmermann, Microb. Biotechnol. 2017, 10, 1308, DOI: 10.1111/1751-7915.12710

[25] R. J. Muller, H. Schrader, J. Profe, K. Dresler, W. D. Deckwer, Macromol. Rapid Commun. 2005, 26, 1400, DOI: 10.1002/marc. 200500410.

[26] Å. M. Ronkvist, W. Xie, W. Lu, R. A. Gross, Macromol. 2009, 42, 5128, DOI: $10.1021 / \mathrm{ma} 9005318$.

[27] D. Ribitsch, E. Herrero Acero, K. Greimel, A. Dellacher, S. Zitzenbacher, A. Marold, R. D. Rodriguez, G. Steinkellner, K. Gruber, H. Schwab, G. M. Guebitz, Polymers 2012, 4, 617, DOI: 10.3390/polym4010617.

[28] a) S. Sulaiman, S. Yamato, E. Kanaya, J. J. Kim, Y. Koga, K. Takano, S. Kanaya, Appl Environ Microbiol 2012, 78, 1556, DOI: 10.1128/AEM.0672511; b) S. Sulaiman, D. J. You, E. Kanaya, Y. Koga, S. Kanaya, Biochem 2014, 53, 1858, DOI: 10.1021/bi401561p.

[29] C. Sharon, M. Sharon, J. Microbiol. Biotech. Res. 2012, 2, 248.

[30] R. Wei, T. Oeser, J. Then, N. Kühn, M. Barth, J. Schmidt, W. Zimmermann, AMB Express 2014, 4, 44, DOI: 10.1186/s13568-014-0044-9.

[31] F. Kawai, M. Oda, T. Tamashiro, T. Waku, N. Tanaka, M. Yamamoto, H. Mizushima, T. Miyakawa, M. Tanokura, Appl. Microbiol. Biotechnol. 2014 98, 10053, DOI: 10.1007/s00253-014-5860-y.

[32] J. Gong, T. Kong, Y. Li, Q. Li, Z. Li, J. Zhang, Polymers 2018, 10, DOI: 10.3390/polym 10121326.

[33] D. Danso, C. Schmeisser, J. Chow, W. Zimmermann, R. Wei, C. Leggewie, X. Li, T. Hazen, W. R. Streit, Appl. Environ. Microbiol. 2018, 84, DOI: 10.1128/aem.02773-17.

[34] A. Farzi, A. Dehnad, A. F. Fotouhi, Biocatal. Agricultural Biotechnol. 2019, 17, 25, DOI: 10.1016/j.bcab.2018.11.002.

[35] S. Yoshida, K. Hiraga, T. Takehana, I. Taniguchi, H. Yamaji, Y. Maeda, K. Toyohara, K. Miyamoto, Y. Kimura, K. Oda, Science 2016, 351, 1196, DOI 10.1126/science.aad6359.

[36] a) J. Then, R. Wei, T. Oeser, M. Barth, M. R. Belisario-Ferrari, J. Schmidt, W Zimmermann, Biotechnol. J. 2015, 10, 592, DOI: 10.1002/biot.201400620 b) S. Chen, X. Tong, R. W. Woodard, G. Du, J. Wu, J. Chen, J. Biol. Chem. 2008, 283, 25854; c) E. Herrero Acero, D. Ribitsch, G. Steinkellner, K. Gruber, K. Greimel, I. Eiteljoerg, E. Trotscha, R. Wei, W. Zimmermann, M. Zinn, A. Cavaco-Paulo, G. Freddi, H. Schwab, G. Guebitz, Macromol. 2011, 44, 4632, DOI: 10.1021/ma200949p; d) X. Hu, U. Thumarat, X Zhang, M. Tang, F. Kawai, Appl. Microbiol. Biotechnol. 2010, 87, 771, DOI 10.1007/s00253-010-2555-x; e) A. Lykidis, K. Mavromatis, N. Ivanova, I. Anderson, M. Land, G. DiBartolo, M. Martinez, A. Lapidus, S. Lucas, A. Copeland, P. Richardson, D. B. Wilson, N. Kyrpides, J. Bacteriol. 2007, 189 2477, DOI: 10.1128/JB.01899-06; f) D. Ribitsch, E. H. Acero, K. Greimel,
I. Eiteljoerg, E. Trotscha, G. Freddi, H. Schwab, G. M. Guebitz, Biocatal. Biotransform. 2012, 30, 2, DOI: 10.3109/10242422.2012.644435; g) L. Su, R. W. Woodard, J. Chen, J. Wu, Appl. Environ. Microbiol. 2013, 79, 4192, DOI: 10.1128/AEM.00239-13; h) U. Thumarat, T. Kawabata, M. Nakajima, H. Nakajima, A. Sugiyama, K. Yazaki, T. Tada, T. Waku, N. Tanaka, F. Kawai, J. Biosci. Bioengin. 2015, 120, 491, DOI: https://doi.org/10.1016/j. jbiosc.2015.03.006.

[37] U. T. Bornscheuer, Science 2016, 351, 1154, DOI: 10.1126/science.aaf2853.

[38] G. J. Palm, L. Reisky, D. Boettcher, H. Mueller, E. A. P. Michels, M. C. Walczak, L. Berndt, M. S. Weiss, U. T. Bornscheuer, G. Weber, Nat. Comm. 2019, 10, DOI: 10.1038/s41467-019-09326-3.

[39] S. Joo, I. J. Cho, H. Seo, H. F. Son, H. Y. Sagong, T. J. Shin, S. Y. Choi, S. Y. Lee, K. J. Kim, Nat. Commun. 2018, 9, 382, DOI: 10.1038/s41467-01802881-1.

[40] a) T. Fecker, P. Galaz-Davison, F. Engelberger, Y. Narui, M. Sotomayor, L. P. Parra, C. A. Ramirez-Sarmiento, Biophys. J. 2018, 114, 1302, DOI: 10.1016/j.bpj.2018.02.005; b) H. P. Austin, M. D. Allen, B. S. Donohoe, N. A. Rorrer, F. L. Kearns, R. L. Silveira, B. C. Pollard, G. Dominick, R. Duman, K. El Omari, V. Mykhaylyk, A. Wagner, W. E. Michener, A. Amore, M. S. Skaf, M. F. Crowley, A. W. Thorne, C. W. Johnson, H. L. Woodcock, J. E. McGeehan, G. T. Beckham, Proc. Nat. Acad. Sci. USA 2018, 115, E4350, DOI: 10.1073/pnas.1718804115; c) X. Han, W. Liu, J. W. Huang, J. Ma, Y. Zheng, T. P. Ko, L. Xu, Y. S. Cheng, C. C. Chen, R. T. Guo, Nat. Commun. 2017, 8, 2106, DOI: 10.1038/s41467-017-02255-Z.

[41] B. Liu, L. H. He, L. P. Wang, T. Li, C. C. Li, H. Y. Liu, Y. Z. Luo, R. Bao, Chembiochem 2018, 19, 1471, DOI: 10.1002/cbic.201800097.

[42] Y. Ma, M. Yao, B. Li, M. Ding, B. He, S. Chen, X. Zhou, Y. Yuan, Engineering 2018, 4, 888, DOI: 10.1016/j.eng.2018.09.007.

[43] C. C. Liu, C. Shi, S. J. Zhu, R. S. Wei, C. C. Yin, Biochem. Biophys. Res. Comm. 2019, 508, 289, DOI: 10.1016/j.bbrc.2018.11.148.

[44] H. F. Son, I. J. Cho, S. Joo, H. Seo, H. Y. Sagong, S. Y. Choi, S. Y. Lee, K. J Kim, ACS Catal. 2019, 9, 3519, DOI: 10.1021/acscatal.9b00568.

[45] a) F. Kawai, T. Kawabata, M. Oda, Appl. Microbiol. Biotechnol. 2019, 103, 4253, DOI: 10.1007/s00253-019-09717-y; b) I. Taniguchi, S. Yoshida, K. Hiraga, K. Miyamoto, Y. Kimura, K. Oda, ACS Catal. 2019, 9, 4089, DOI: 10.1021/acscatal.8b05171.

[46] a) Carbios, Innovation Catalyst for a True Circular Economy of Plastics, https://carbios.fr/en/, accessed 297.06.2019; b) C. Boisart, E. Maille, US 10,124,512, 2018; c) E. Maille, US20170114205A1, 2019.

[47] European Biotechnology Life Science and Industry Magazine, Novozymes partners with Carbios subsidiary Carbiolice https://european-biotechnology. com/up-to-date/latest-news/news/novozymes-partners-with-carbios-subsidiary-carbiolice.html, accessed 26.06.2019.

[48] M. Salvador, U. Abdulmutalib, J. Gonzalez, J. Kim, A. A. Smith, J. L. Faulon, R. Wei, W. Zimmermann, J. I. Jimenez, Genes 2019, 10, 15, DOI: 10.3390/genes 10050373 . 